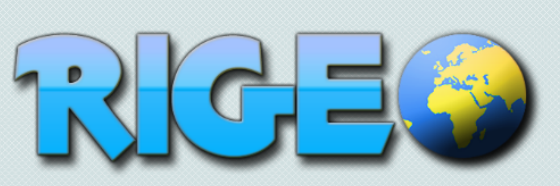

\title{
Awareness of Primary Teachers about Teaching Location and Direction Concepts
}

\author{
Nilgün DAĞ' ${ }^{1}$ \\ Mersin University, Mersin \\ TURKEY
}

\author{
Bülent AKSOY2 \\ Gazi University, Ankara \\ TURKEY
}

\author{
Halis Adnan ARSLANTAŞ ${ }^{3}$ \\ Eskişehir Osmangazi University \\ Eskișehir, TURKEY
}

\footnotetext{
${ }^{1}$ Corresponding author: Assoc. Prof.; Mersin University, Faculty of Education, Department of Primary Education, Ciftlikkoy Campus, Mersin, TURKEY. dagnilgundag [at] gmail.com. ORCID: 0000-0002-5084-6472

2 Prof. Dr. Gazi University, Faculty of Education, Department of Social Studies Education, Ankara, TURKEY. baksoy28 [at] gmail.com. ORCID: 0000-0002-7181-8008

${ }^{3}$ Assoc. Prof.; Eskişehir Osmangazi University, Department of Educational Science, Educational Philosophy, Social and Historical Fundamentals of Education, Meșelik Campus, Eskișehir, harslantas [at] ogu.edu.tr. ORCID: 0000-0002-5289-9017
}

\begin{abstract}
The aim of this study is to determine the awareness of primary teachers about the teaching of location and direction concepts. The study was designed according to a qualitative research model, and the data was collected through a semistructured interview form developed by researchers consisting of open-ended questions. The study group consisted of seven primary teachers working in Eskișehir, Mersin and Nevșehir provinces of Turkey. In determining the study group, the convenience sampling technique was used from purposeful sampling methods. The interviews were conducted in the fall semester of the 2020-2021 academic year and the data obtained were analyzed by content analysis. The study findings showed that participants were aware that the concepts of "location" and "direction" constitute a necessity in the curriculum and that the teaching of these concepts provides benefits and convenience to students both in school life and in daily life practice.
\end{abstract}

\section{Keywords}

Location, Direction, Primary Teacher

To cite this article: Dağ, N.; Aksoy, B.; Arslantaş, H. A. (2021). Awareness of primary teachers about teaching location and direction concepts. Review of International Geographical Education (RIGEO), 11(1), 42-61. doi: 10.33403rigeo.844720 
Along with the "Learning to Think Spatially" report published by the National Research Council (NRC) in the United States, spatial thinking has become one of the most researched topics in recent years. Spatial thinking, which is also an integral part of daily life, is a prerequisite skill that is central to learning and performing many skills. It refers to the ability to see and understand two or more objects related to each other and to itself and is the basis of many learning. It is the main skill that focuses not only on geographical learning, but also on various activities such as understanding metaphors, being good at finding ways, interpreting works of art, molecular modeling, generating geometric evidence, and interpreting astronomical data (NRC, 2006, p. 94). Understanding the phases of the moon, visualizing chemical structures, learning about plate tectonics, or reading a graph depends on understanding spatial knowledge and phenomena (Gagnier \& Fisher, 2016). In addition, spatial thinking is so deeply embedded in daily life activities that it may not always be possible to realize its function.

Spatial thinking distance, location, direction, relationships, movement, and change the location and movement in space and our own objects by using mentally or physically, to know and to understand and contains developed from an early age to be a complex cognitive skill that can be taught and learned. Although spatial skills are assumed innate, evidence from research suggests they can be taught and improved (Uttal, Meadow, Tipton, Hand, Alden, Warren \& Newcombe, 2013).

Actually, spatial thinking is a fundamental part of K-12 education and is the focus of many courses and STEM activities such as Life Science, Social Studies, Science and Mathematics. Children are first taught to learn the names and forms, in elementary school, about some of the main geographical concepts such as location, distance, direction, angle, continents, oceans, etc.; after that, they gradually master the use of maps, spheres and coordinates and begin to acquire the ability to use spatial technologies. Spatial technologies ${ }^{1}$ (such as GPS, Google Earth) require spatial thinking and location analysis skills. These technologies support students ' spatial

${ }^{1}$ Dubois and Rousseau (2020, p. 29) make the following note regarding the loss of humanity's sense of direction in their Philosophy of Birds: "Unlike Mongolians and migratory birds, most of us have completely forgotten our sense of direction. We no longer know how to read the landscape, the star or the natural world. These things have become the mute decor of our environment. We have eyes but we are blind, walking and driving guided only by the directions of a robotic voice emanating from a GPS or smartphone. We have left the essential task of navigation to others -or worse still, to machines. What would we do if we were left alone in a forest or in the hills, even just thirty miles from home, and could not ask for directions or look at a map? How long would we spend wandering before eventually, perhaps, finding the right way? In addition, considering all this, have we not lost the most important aspect of travel, the one that could give us real power -the basic ability to find our way, to establish the right path for ourselves? It is hardly surprising that, no longer able to orientate ourselves, many of us often feel lost in our lives. We claim to know everything, to be the masters of modern life, but in nature, even "civilized" nature, we are as vulnerable as fledglings." feel lost in our lives. We claim to know everything, to be the masters of modern life, but in nature, even "civilized" nature, we are as vulnerable as fledglings." 
thinking abilities and help them understand natural and cultural events (Çepni, 2019).

The ability to perceive spatially ${ }^{2}$ is one of the basic life skills included in the 2018 Life Science Course Curriculum and the 2018 Social Studies Course Curriculum. Location analysis skill is a skill that is intended to be acquired by feeding in skills such as map literacy and space perception in the social studies curriculum (Çepni, 2019, p. 369).

Achievements related to the teaching of the concepts of "location" and "direction" are shown in Table 1 in Life Science and Social Studies Course Curriculum. As can be seen in Table 1, there are acquisitions at each grade level related to the acquisition of "location" and "direction" knowledge.

Table 1

Achievements Related to Teaching the Concepts of "Location" and Direction" in Life Science and Social Studies Course Curriculum

\begin{tabular}{|c|c|c|c|}
\hline Course & Grade & $\begin{array}{l}\text { Acquisition } \\
\text { Number }\end{array}$ & Acquisition \\
\hline Life Science & 1 & LS.1.1.4. & Finds the place of the class in the school. \\
\hline Life Science & 1 & LS.1.2.3. & $\mathrm{S} /$ He describes the location of his house. \\
\hline Life Science & 2 & LS.2.1.5. & $\begin{array}{l}\text { Introduces the immediate surroundings } \\
\text { of the school. }\end{array}$ \\
\hline Life Science & 2 & LS.2.6.8. & $\begin{array}{l}\text { It shows directions by observing the } \\
\text { sun. }\end{array}$ \\
\hline Life Science & 3 & LS.3.1.5. & S/He sketches his class and school. \\
\hline Life Science & 3 & LS.3.2.3. & $\begin{array}{l}\text { S/He sketches the place where his house } \\
\text { is located. }\end{array}$ \\
\hline Life Science & 3 & LS.3.6.3. & $\begin{array}{l}\text { It finds its aspects by taking advantage } \\
\text { of nature. }\end{array}$ \\
\hline $\begin{array}{l}\text { Social } \\
\text { Studies }\end{array}$ & 4 & SS.4.3.1. & $\begin{array}{l}\text { It makes inferences about the location of } \\
\text { any place around it. }\end{array}$ \\
\hline $\begin{array}{l}\text { Social } \\
\text { Studies }\end{array}$ & 4 & SS.4.3.2. & $\begin{array}{l}\text { S/He sketches the places } s / \text { he uses in } \\
\text { everyday life. }\end{array}$ \\
\hline
\end{tabular}

Direction is defined in the Turkish dictionary (TDK, 1988, p. 1642) as "a place with respect to a certain point", while location ${ }^{3}$ is described as "the state or form of posture of someone or something in a place, location” (TDK, 1998, p. 895). Both concepts are a prerequisite for all kinds of spatial analysis and are the basis for the ability to perceive space. It is necessary to have gained the ability to perceive the

\footnotetext{
2 "Perceiving the space, determining his own position in the space, creating the space in his mind by obtaining information about the space, finding and describing the place based on the route knowledge obtained through the recognition and understanding of the space can be expressed as the actions of the individual regarding spatial cognition." (Köşker, 2012, p. 162).

3Location marks a more precise point than "place".
} 
space to be able to determine the position of the individual in his/her daily life, to determine his position and direction, to grasp the geographical information about the place (Safi, 2010), to be able to use direction instructions that inform how to arrive at a place, etc. In this context, it is extremely valuable to comprehend the concepts of location and direction from an early age, to form cognition and perception towards space, to make drawings based on information about place, to understand the drawings of place and to animate the real shape in the mind. Preparation of development plan map knowledge and skills to be acquired, homeland security, and safety, and land use studies such as the determination of the route for individuals, military, and economic life and in some cases, necessary for navigation and location for various purposes and is essential for daily life, such as (Koç, Aksoy, \& Çiftçi, 2017, p. 303).

Topics such as "location", "place" and "direction" are key concepts that form the basis for knowledge in Geography and are necessary for activities in each process of life. It is a basic knowledge and skill that is sometimes needed when going to school, home, market or movie, and sometimes when visiting another country (Çepni, 2019, p. 371). Indeed, children and adults need to acquire spatial skills. However, in a study that investigated the level of social perception of basic map skills such as location and direction finding (Tuna, Demirci \& Gültekin, 2012), it was found that the level of knowledge and skills of society in this area was quite low. Only $50 \%$ of the participants in the study were able to show the desired direction correctly. Although most of them recognized the compass, 38\% of the participants were able to accurately express the direction they were asked to show with the compass. $47 \%$ of respondents can show their location on the map, while this figure has decreased to $30 \%$ when describing the district municipality in which they live. In a study conducted by Sönmez and Aksoy (2012), the direction-finding skills of secondary school students differed in favor of metropolitan ones of the type of settlement.

Guidelines about location and direction can be difficult to teach primary schoolage children. However, there are many fun activities that can be included in the lessons to make this topic more understandable and fun. Learning how to give directions or marking the school's location on a map drawn on the primary board are extremely interesting activities for students. Again, by giving a starting point on the map and determine the point to an array direction $\mathrm{X}$ can be reached on alternative from students about how important it is to get directions, and create a maze in the labyrinth of the order or class to the students in class the way of your teammates to provide guidance for and giving directions, even if you cause bodily injury if competition in the form of papers or apply in the case of this activity the participation of elementary school students working on a design that will show up are activities to enjoy. 


\section{Methodology}

In this section, data collection and data analysis procedures are explained in addition to the model and design of the research. In addition, explanations regarding validity and reliability are given.

\section{Research Design and Method}

This study was conducted based on a qualitative research model and the qualitative "case study" design was used in the study. A qualitative research model was preferred in this study on the basis of observing that the subject of the study was considered in a limited way in the national literature and that quantitative research methods were mainly used in current studies. Qualitative research models are useful in exploring the meaning that people give to the events they experience (Bogdan \& Biklen, 2003) and allow the researcher to understand in depth what is happening on this issue are also among the reasons that lead to this choice.

The study used a "case study" approach to explore primary teachers' awareness of the teaching of the concepts of location and direction. Case studies are concerned with "process" rather than outcomes, "context" rather than specific elements affecting the phenomenon, and "discovery" rather than verification (Merriam, 1998; cited by: Leymun, 2017, p. 371). In this context, the most appropriate questions for case study-based research are the "how" and "why" questions. The current research was built on the question "How do primary teachers' awareness of the teaching concepts of "location" and "direction"?".

\section{Study Group}

The research was conducted in the fall semester of the 2020-2021 academic year with seven primary teachers who were working in the provinces of Eskișehir, Mersin and Nevşehir in Turkey. Convenience sampling was preferred in determining the study group. Convenience sampling is a type of sampling that provides convenience to researchers in terms of cost and time (Patton, 1990).

Seven primary teachers formed the study's working group. Four of the participants are female and three are male. The teacher with the lowest professional seniority has seven years experience, and the teacher with the highest professional seniority has 30 years experience. Five of the primary teachers participating in the study have a Bachelor's degree, while five have a Master's degree. Two of the teachers continue to study for a Master's degree and one teacher studies for a Doctorate degree. Two of the primary teachers are teaching Grade 4, two of the primary teachers are teaching Grade 3, two of the primary teachers are teaching Grade 2, and one of the primary teachers teaches Grade 1. Information about participants is presented in Table 2. In addition, for de-identification in the study, code names such as "MT" for male participants and "FT" for female participants were used instead of the real names of the participants. 
Dağ, N.; Aksoy, B.; Arslantaș, H. A. (2021). Awareness of primary teachers about teaching location...

Table 2

Descriptive Characteristics of Participants

\begin{tabular}{llllllll}
\hline Nick Name & FT1 & FT2 & FT3 & FT4 & FT1 & FT2 & FT3 \\
\hline Age & 35 & 38 & 36 & 29 & 35 & 33 & 50 \\
Graduate & $\mathrm{U}^{*}$ & $\mathrm{U}$ & $\mathrm{U}$ & $\mathrm{U}$ & $\mathrm{MD}$ & $\mathrm{MD}$ & $\mathrm{U}$ \\
Professional Seniority & 12 & 14 & 16 & 7 & 11 & 12 & 30 \\
Grade & 1 & 2 & 3 & 3 & 4 & 2 & 4 \\
\hline
\end{tabular}

* G: Undergraduate ** MD: Master Degree

\section{Data Collection Process}

Data sources in case study-based research are "documents, archival records, interviews, observations (direct or participant), and physical artifacts". The main data source used in this research is the interview. Interviews provide an understanding of how people see the world, their personal points of view, and their experiences by providing a roof over which individuals can explain unobservable behavior with their own sentences of emotions and understandings (Patton, 1990). The reason why interview technique is preferred in this study is to be able to evaluate the awareness arising from the opinions expressed based on the experience of primary teachers with first-hand data.

Data from the study was collected over a period of one week in the form of an online interview through an open-ended semi-structured interview. The researchers conducted a preliminary study independently of each other on the interview questions and discussed the interview questions they posed as a result of the preliminary studies in focus group meetings and decided on the final questions. Researchers identified interview questions based on their personal observations, national and international literature review, and primary life. Interview questions were submitted to the opinion of five experts: two experts were educational programmers and three experts were primary educators ${ }^{4}$ (Glesne, 2013). The questions were edited in accordance with incoming criticism and recommendations, and a mini pilot application was made. The pilot application form was applied to Grade 3 teachers. As a result of the application, the evaluation occurred and the interview questions were given their final form. The questions posed to primary teachers in the interviews are as follows:

1. What is your opinion about the reason for the inclusion of the concepts "location" and "direction" in the curriculum?

2. What lessons do you think the concepts of "location" and "direction" relate to in primary school? Can you explain the reasons?

4"What are your thoughts about the situations that an individual who does not have the knowledge of the concepts of "location" and "direction" may encounter? question has been added. 
3. How do you teach the concepts of "location" and "direction"? (What methodstechniques, tools-materials and materials how do you use them?)

4. What do you think is the practical benefit of providing knowledge about the concepts of "location" and "direction"?

5. What are your thoughts about situations an individual may encounter who does not have knowledge about the concepts of "location" and "direction"?

In addition to these questions, probing questions have been added to increase the depth of the data collected. The online data collection process was conducted between 13-17 November 2020 and the interviews lasted an average of 20 minutes.

\section{Data Analysis}

There are no systematic rules for analyzing data obtained in case-based research. However, there must be a logic and a framework behind the analysis (Yin, 1998). In this study, data was analyzed using the content analysis method. In content analysis, the goal is to reach concepts and relationships that can explain data. The main meanings found in the analysis of data are called "themes" (Patton, 1990). The data obtained in this study are themed. For this purpose, first of all, the research group's responses to interview questions were transferred to a computer environment. $A$ total of 28 pages of data were obtained from interview records.

The raw data was then read separately by the researchers, subjected to content analysis, the draft themes were determined, and the responses of the primary teachers were encoded. The researchers ' coding was compared and the consensus percentage was calculated as $90 \%$ with the formula "Reliability = Consensus / (Consensus + Dissensus) x 100" put forward by Miles and Huberman (1994). Codes that differed in opinion were reviewed again, discussed and agreed upon, giving the themes, sub-themes and encodings their final version. The themes and codifications under each research question are presented in tables and the statements of the primary teachers are included through direct quotes.

\section{Validity and Reliability}

In order to increase the validity of the research, the data obtained from the interviews were reported in detail and in the form of direct citations. In order to increase reliability, a confirmation review was conducted. The researchers conducted a two-week preliminary study of interview records independently of each other to identify codes and themes. The themes revealed in the preliminary study were discussed and evaluated in focus group meetings and consensus was reached. The themes obtained were also encoded by another researcher specializing in the field, and the results were compared. For the reliability calculation of the research, the percentage of match [Reliability $=$ Consensus / (Consensus + Dissensus) $x$ 100] proposed by Miles and Huberman (1994) was used. Percentage of numbness in the study as a result of calculations. Calculated as 90 . The fact that 
the percentage of match obtained as a result of this process exceeds $70 \%$ means that the data obtained from the data collection tool is considered reliable (Miles \& Huberman, 1994).

Since the convenience sampling technique provides little control over the sampling method -in order to prevent improper participation in research that may arise from this sampling technique- a control question ("Have you had experience in teaching "location" and "direction" concepts?") was asked to the participants and validity was tried to be increased.

\section{Findings}

In this section, the results are presented. The views of the primary teachers about the teaching of the concepts of "location" and "direction" as analyzed in response to the interviews questions.

\section{Justification for the Inclusion of the Concepts of "Location" and "Direction" in the Curriculum}

Primary school teachers were asked the question: "What do you think is the reason for the inclusion of the concepts "location" and "direction" in the curriculum?". The answers given by primary teachers were collected under the theme of "Instructional Necessity". Under this theme, sub-themes related to the state of "Necessity in primary learning" and "necessity in everyday life" appeared. The results of the analysis of the data obtained from the opinions of the primary teachers are presented in Figure 1.

Primary teachers noted that the concepts of "location" and "direction" are a requirement in the curriculum, for example, students should follow instructions, understand visuals, act independently, and understand spatial relationships. In addition, students determine their place, direction and location; they know their place, environment and region; and they acquire individual and global environmental awareness. It was also stated that they believe these concepts are included in the curriculum. In other words, teachers associated the reason for the inclusion of the concepts of "location" and "direction" in the curriculum with the needs in everyday life. 


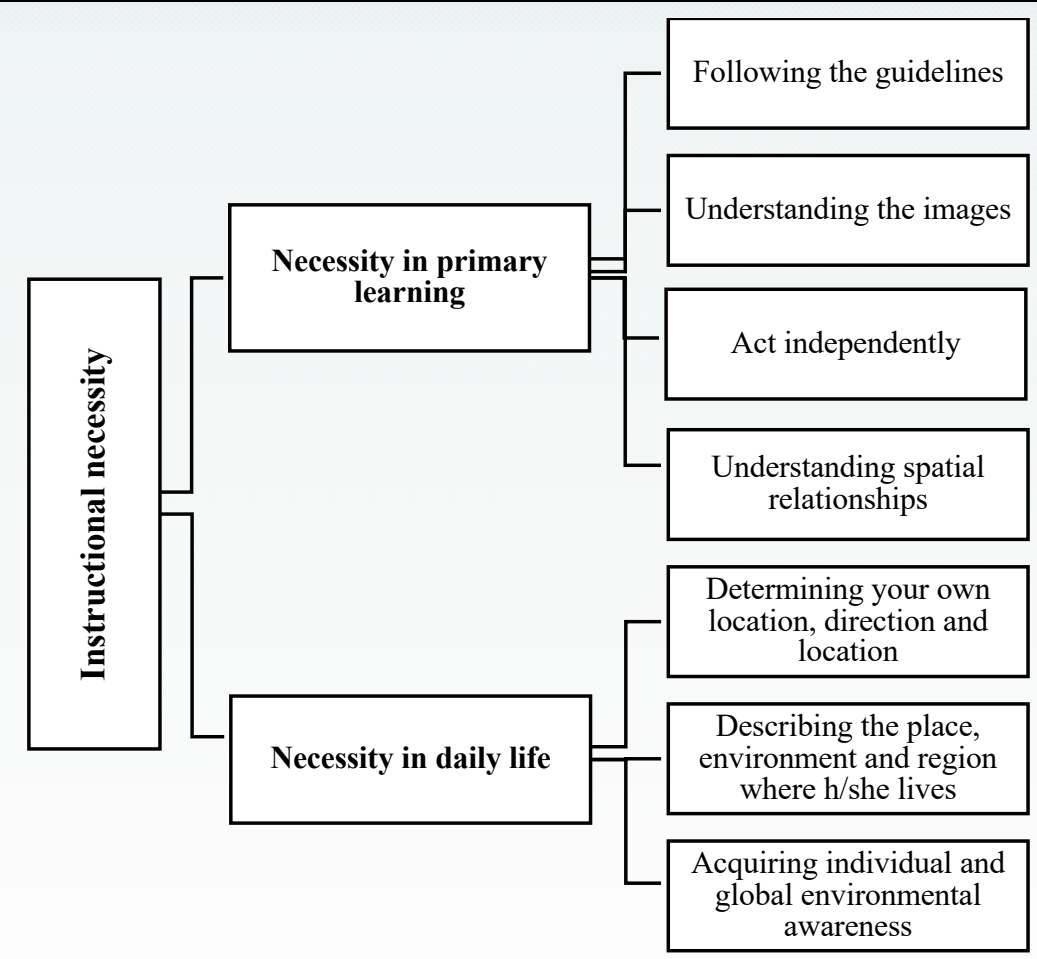

Figure 1. Justification for the Inclusion of the Concepts of "Location" and "Direction" in the Curriculum

Some of the expressions of primary teachers regarding the reason for the inclusion of the concepts "location" and "direction" in the curriculum are as follows:

Knowing the right-left of the child is one of the issues that we think will be useful in everyday life. In addition, at the basic level of this, we try to teach children in Primary School, starting from 1st grade. For example, you can use images on the right-left. For example, we deal with a topic in the book. When I say, do the one on the right, the child must know the right. To clearly follow our guidelines [MT1].

How does a new student find a class? How does $\mathrm{s} /$ he find his class after his parents quit? This is especially important for the student to stand on his/her own feet, that is, to become independent [MT2].

In terms of their understanding of spatial relations, that is, if they do not know spatial relations, we cannot deepen mathematics. [FT1]

\section{The Relationship between "Location" and "Direction" Concepts and Courses in Primary School}

The following question was asked to the participants in the study: "What lessons do you think the concepts of "location" and "direction" relate to in primary school?". Seven out of seven primary teachers responded they associate the concepts of "location" and "direction" with the lessons from Life Science and Social Studies. Two of the primary teachers stated that they also found it related to Science, three teachers said it was related to Mathematics courses; three teachers said it was 
related to Turkish lesson. "Location" and "direction" is associated with the curriculums of Life Science, and Social Studies as a subject of acquisitions for these concepts to be included and to be given under the auspices of these two lessons. Some of the primary teachers' expressions on which concepts of "location" and "direction" relate to lessons in primary school are as follows:

It is a subject of the Life Studies lesson in the 1st, 2nd and 3rd grades, and these subjects are also included in these lessons [MT1].

The expression of the concepts of location and direction is cognitively related to the course of Life Science and Social Studies [FT1].

Life Science, and of course it is the main topic in Social Studies. However, I think it's also related to Mathematics. I mean, it is in Math. It is also in Science. For example, we call it the location of the world or something like that, where we are, where we are, like this, talking to them about the equator too [FT3].

\section{Teaching the Concepts of "Location" and "Direction"}

The following question was asked to the participants in the study: "How do you teach the concepts of "location" and "direction"?". The answers given by primary teachers were collected under the theme of "Teaching-Learning Process". Under this theme, sub-themes related to "in-class activities" and "out-of-class activities" have emerged. The results of the analysis of the data obtained from the opinions of the primary teachers are presented in Figure 2.

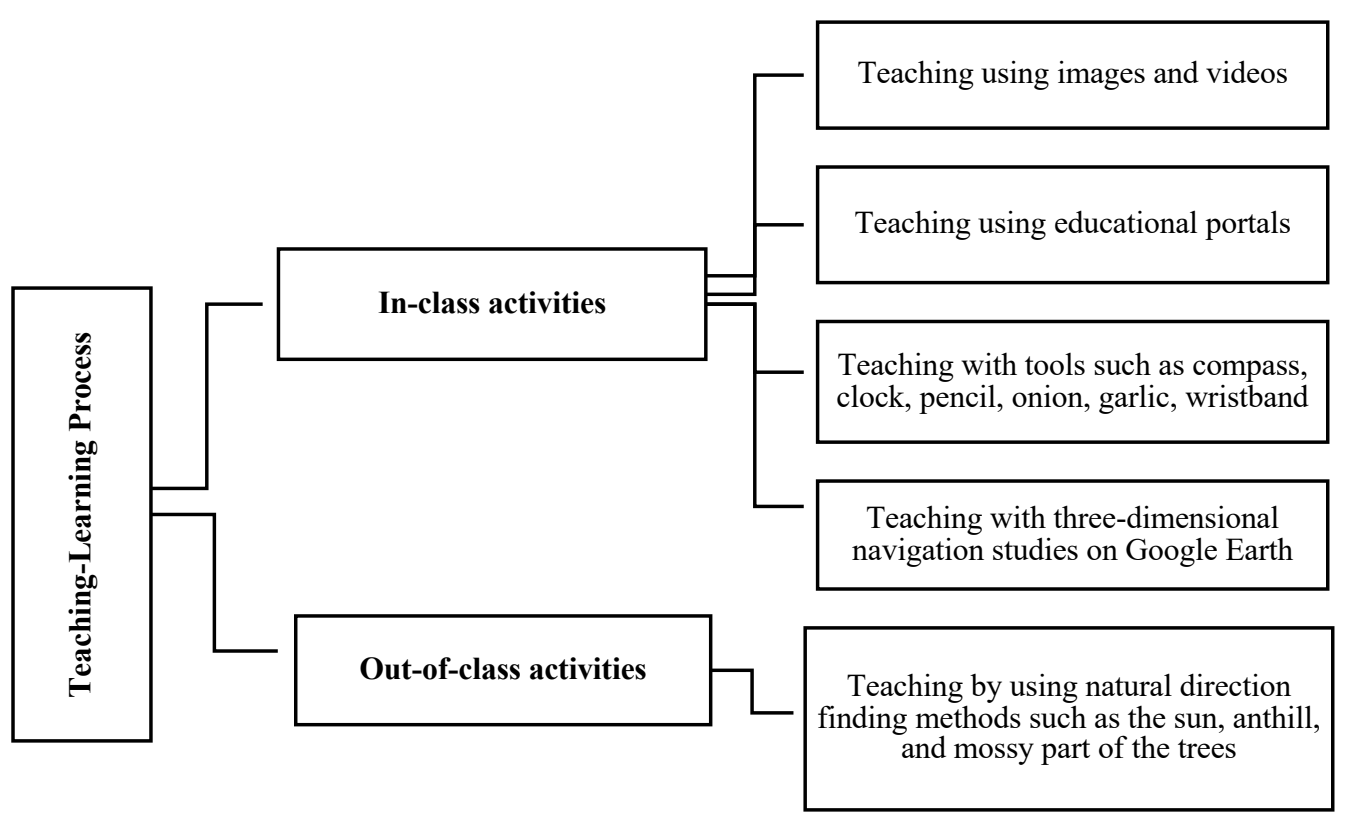

Figure 2. Teaching the Concepts of "Location" and "Direction"

All seven of the primary teachers stated that they taught the basic concepts of right-left, front-back, under-top, down up by associating them with concrete objects 
such as onion-garlic, pen, ribbon, or using accessories such as wristbands, watches. All seven of the primary teachers stated that primary school students had difficulty understanding the right-left terms, and they tried to conceptualize these terms by associating them mainly with the "penheld hand" or "written hand". Some of the expressions of primary teachers in this context is as follows:

I tell children that my method, which I humbly use myself, child, is your right hand, the hand in which you hold a pen, the hand in which you write, and I try to dictate it. We teach that your left hand, the hand you do not use, the hand you do not write, is like your left hand. Alternatively, children usually carry a watch on their arm. If you have an accessory watch on your arm, look, and the arm with the watch is your right arm, like my son or like my daughter. Either we do this with the help of an accessory path, or we associate it with an object that it holds. Because you give rights to the right and left child, which are very abstract concepts. We try to conceptualize this by associating it with a concrete tool [MT1].

This is how I teach the concepts of right-left, called the hand or other hand in which we hold a pen. Or I wrote it on the wristbands when I was a freshman. There were those who did not know and confused. He/She is in third grade now, but he is still mixing right-left, guys. [FT3]

Here I say, for example, "what hand do you write with when you're in first grade?". I usually say, "We take pens in our right hand", because it is written with the right hand. However, the boy takes it to the left. Because right-left does not know, kid. Even when writing, basically the child needs to know right and left [FT4].

All seven of the primary teachers expressed their support for primary teaching with examples of activities in textbooks and some source books. The primary teachers used concrete tools and materials such as compass, and directional diagrams in teaching the main and intermediate aspects. Currently, one of the primary teachers is conducting educational work remotely due to the pandemic, with images and videos from some educational portals (okulistik, morpa campus, etc.) stated that he benefited. Some of the expressions of primary teachers in this context are as follows:

... Children are also having a hard time. This is how we know that in mathematics, our average in Turkey is certain, we cannot understand mathematics, we cannot understand English. And in the directions, the situation seems to be a little close to them. It's not like them, so he doesn't understand how much we embody some of them. Because it's a bit like a mathematical concept. But it's permanent with events. For example, there are educational portals such as school. We're taking advantage of them. It attracts the attention of children because it is visual, animated, they are really a little more effective [MT3].

Certainly, doesn't forget when he takes them out, shows them the direction in which the sun rises, and the child opens arms. In this way, but if we talk about it without doing any activity in the normal class, they can't learn. I'm afraid it's not permanent [MT1].

We're bringing the compass to our class. With children, we show them all after we put this dark part on a flat floor, or by circulating it from hand to hand, so that the dark part shows the north, of course, when the child shows the north, the opposite side is south, the right side is east, the left side is west [FT3]. 
Our main source is the textbook. First, I process it from the textbook. I then take advantage of educational portals like morpacampus, like the school. From now on, I'm bringing a compass to our class. After that, we use the direction diagram. We use a directional diagram that we have prepared ourselves or prepared for children in visual arts class. And we use the schoolyard. And after we learn about the subject, we use the source books as photocopies [MT3].

Only three of primary teachers, "location" and "direction" in the teaching of the concepts stated that they benefited from the map, and the map a person and brings a bird's eye view in the teaching of concepts such as Sketch first; then the direction chart, a mute map, Turkey map, world map, globe application that performs the work with the model in Google Earth tools and materials such as "location" and "direction" to perform remedial activities on the concepts expressed. Some of the expressions of primary teachers in this context is as follows:

I touch on the map every lesson. In every lesson, I always remind children which direction the Black Sea is in, which direction the Mediterranean is in. I think it's very important to have a map in the primary. It's very useful for reinforcement [FT4].

... Also, I use the Google Earth program towards fourth grade. In Google Earth, he sees a world first. You can already translate it in the simulation and play it as you like. Here we are zooming in on Turkey's place in the world. We're getting closer. S/he sees the map of Turkey. As part of the class, the world, the world of Turkey, the province in which we live from Turkey, our school from the province in which we live, already appears on Google Earth. I use these [MT2].

One of the primary teachers stated that he began teaching the concepts of "location" and "direction" with teaching concepts such as right-left, front-back, under-above, down-up; then he realized teaching the concepts of "main and intermediate direction" and then gave place to "map teaching".

First, we start the concepts of place-direction on the right-left, above-behind. it's a topic that extends to giving directions to the fourth grade, drawing sketches. ... So we don't give the kid direct directions when he comes to first grade. We don't name directions like main directions, north Here, East here. First, we start with basic concepts such as our aim, right-left, front-back, above or below. First, the important thing is that the child can find his class. Then, after we find the order, for example, we want to draw a sketch of the class and assign the child its place in the class. In a ready-drawn model, in a sketch, or rather, we do activities with working papers, such as marking the location of the class or marking the location of certain friends in the class. After that, mute maps are very important. And already in this concept of direction, especially the map and the world model, I always try to keep the sphere model in the class.... In the second grade, we now give names to directions. North, south, east, west. We give the main directions. In it, we try to increase its permanence more, at least with connotations such as rising East, setting west, the sun rose East, the sun set west with primary mottos in the form of rising east, setting west. And on the mute map, I'm waiting for the kid to fill in all the forwards. ... Also, I use the Google Earth program towards fourth grade [MT2].

Two of the class teachers, teach the concepts of "location" and "direction" by using a lecture, demonstration, observation, question and answer method-techniques Two of the teachers use lecture, question-answer teaching method and demonstration; three of the teachers use lecture and question-and-answer teaching 
methods. In addition, primary teachers stated that they used natural directionfinding methods such as the sun, anthill, mossy part of trees, Polar Star, as well as direction-finding methods using tools such as compass, clock, pen, onion, garlic, and bracelet. Only three of the primary teachers stated that they used compass and map in teaching the concepts of "location" and "direction". A primary teacher also said he used the sphere model.

\section{Practical Benefit of Providing Knowledge of the Concepts of "Location" and "Direction"}

The following question was asked to the participants in the study: "What is the practical benefit of providing knowledge about the concepts of "location" and "direction"?". The answers given by primary teachers were collected under the theme of "benefits of providing knowledge". Under this theme, sub-themes related to the state of "in teaching-learning process" and "in daily life" emerged. The results of the analysis of the data obtained from the opinions of the primary teachers are presented in Figure 3.

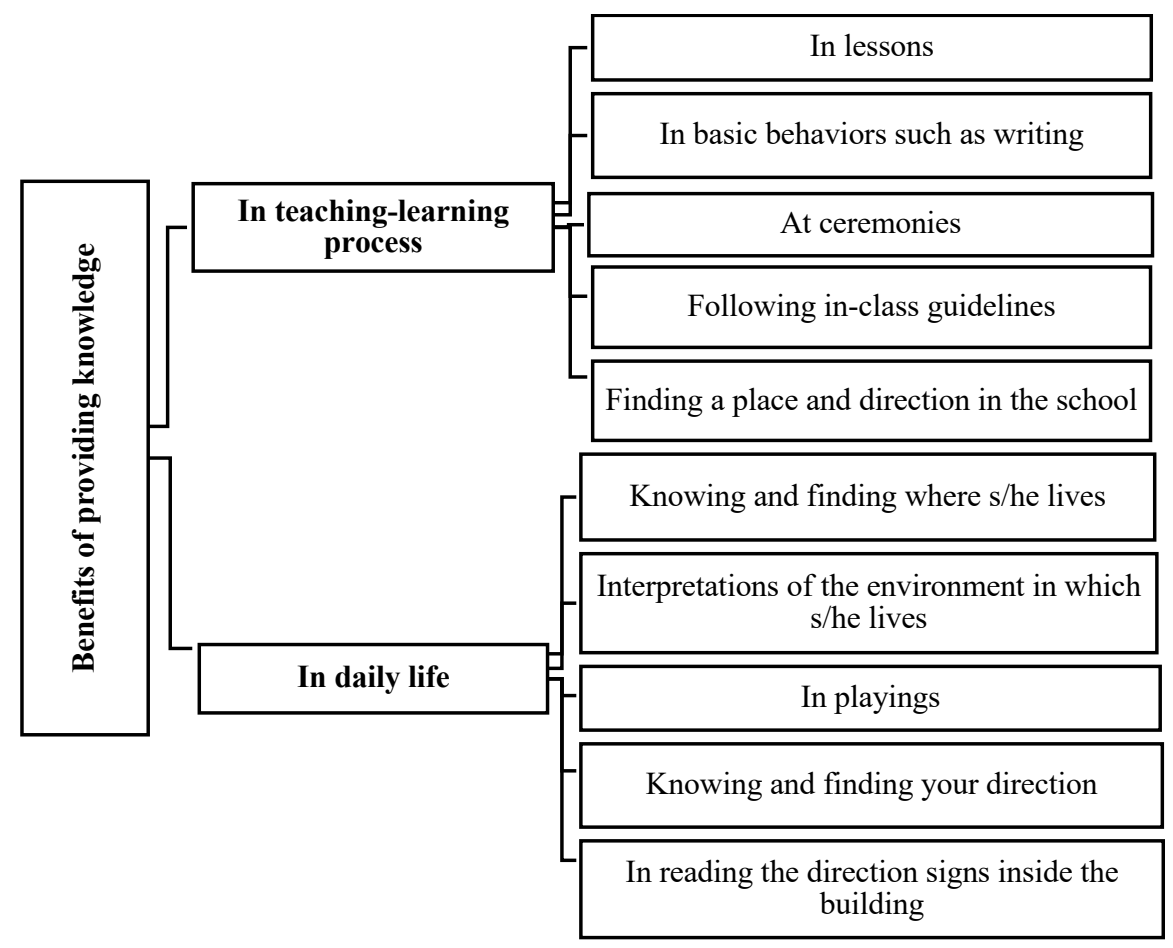

Figure 3. Practical benefit of providing knowledge of the concepts of "location" and "direction"

Primary teachers' explanations are as follows:

For example, it allows you to read directions inside the building. I mean, for example, we go to a hospital, we can go to a justice, we can go to other buildings, the hospital at most, you know, hospitals have grown, so even there, the child can look there and know or not know where the doctor's room or laboratory is, on what floor, on what block, or can't read them in the direction 
of the place, this is reflected in their daily lives, even when they move in an institution from the simplest, that is, in their movements [MT2].

We are huge people, even in us, the concept of location and direction is essential. ... Children also run to the right while playing hide-and-seek or playing dodgeball while the child directs his friend [FT2].

When he is going to describe his home and direction to a friend, of course he needs to know the direction and location information.... Especially for people living in metropolitan cities, the concept of place-direction needs to be known. ... Even when writing, basically the child needs to know right and left. ... That's the basic skill. In first grade, a kid doesn't know his right-left when he writes. Or I'm saying go down the stairs, turn right, the teachers' room is there. But the boy doesn't know right. In his later life, for example, it went to a foreign city. He had to get directions and directions from someone. He needs to know. Something that could affect your whole life [FT4].

It is important that he knows his right-left when we say turn right, turn left in physical education class, for example, when we walk like this, or during certain days and weeks, at ceremonies that we do on April 23 or October 29 [FT3].

First, they can use it when playing games with their friends. They can use this academic knowledge in their conversations. Of course, they use it more in their classes. But it's everywhere in life [FT2].

A person's thoughts about the practical benefit of providing knowledge of the concepts of "location" and "direction" were as follows:

I don't think it's particularly useful for children on a primary school basis. If a student knows or does not know the eastern direction, he will not lose much of his life. Because in everyday life, I'm talking to him about primary school level, but it can be information that doesn't help a seven-year-old much. But we want to give it at a basic level because it will be beneficial going forward. For example, I throw it away, it can relate to anything. Think of an adult, what does he do to pray? It'll lay his prayer rug South, won't it? It says the Qibla is in the south direction. First it tries to find the South. But you'll agree, I don't think it matters much that a seven-yearold doesn't know the directions. But we will give it away because it is a very important win going forward [MT1].

\section{Contribution of Knowing the Concepts of "Location" and "Direction" in the Academic Dimension}

A question - "What are the academic contributions of knowing the concepts of "location" and "direction" to your students?"- was asked to the participants in the study and the answers are given by primary teachers were collected under the theme of "academic contribution". Under this theme, sub-themes related to the state of "cognitive development" and "affective development" emerged. The findings resulting from the analysis of the data obtained from the opinions of the primary teachers are presented in Figure 4. 


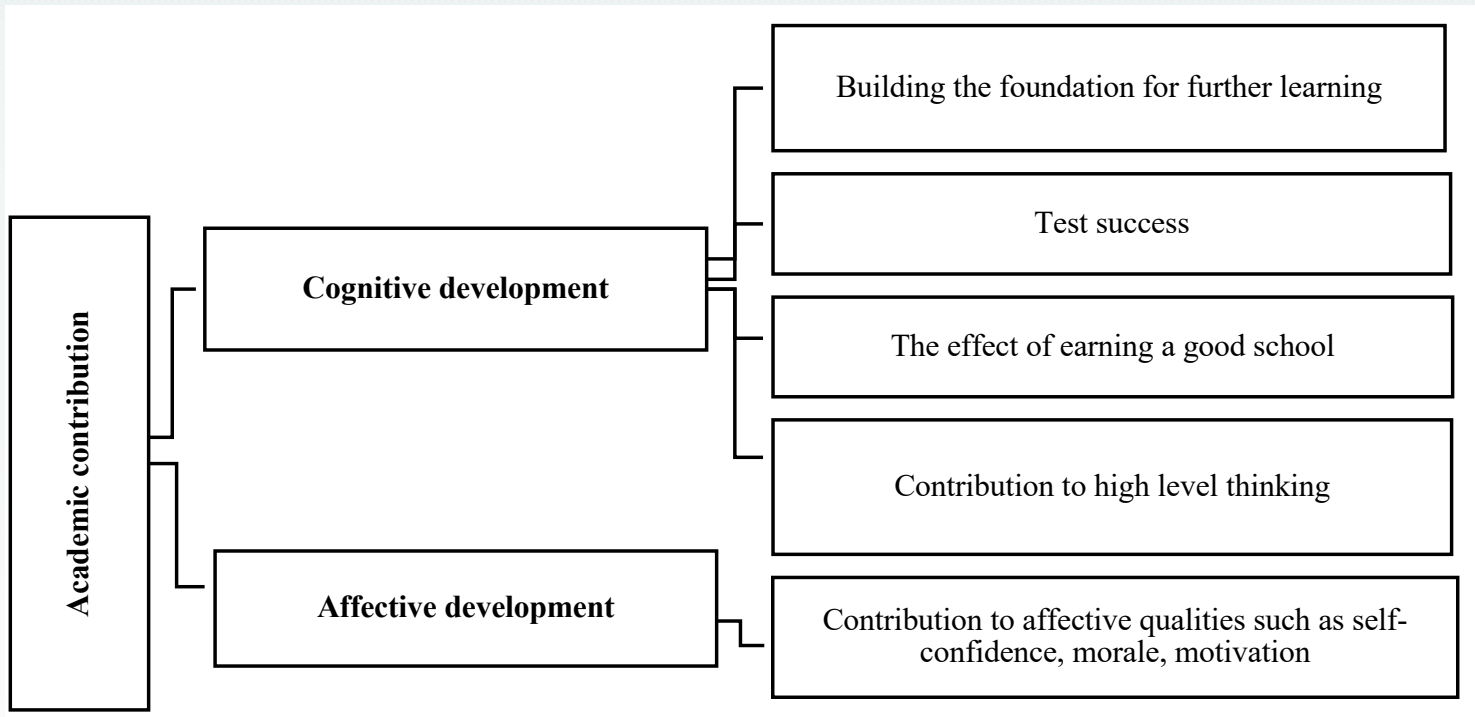

Figure 4. Contribution of knowing the concepts of "location" and "direction" in academic dimension

\section{Primary teachers' explanations are as follows:}

There are a significant number of questions about the concept of direction in the test exams. High school and college exams have questions. In order to win a good school, they need to know the concept of direction. ... It will definitely be preferred. So, it will be a motivating, happy situation as you look at either by your friends or how the smart boy immediately found or something like that [MT3].

\section{It's important for high-level cognitive skills. [MT2]}

I think knowing the location and direction will allow them to succeed academically in other courses... Especially in the next generation of questions about Life Science and mathematics, there are a lot of right-left concepts. Even in rhythmic counting, the number is asked as two rows to the right and two rows to the left [FT2].

It's important for their confidence. It will make their work even easier when they make a connection to these concepts and topics in terms of feeling good or with another course. I would say that this will be a step towards them becoming a more successful individual in academic life [FT1].

One of the primary teachers thought about the academic contribution of knowing the concepts of "location" and "direction" was as follows:

I'll tell you from myself as a teacher. It didn't affect my academic achievement. I don't think the kids will have much of an impact either.... I don't think he'll have any academic problems, to be honest. I don't think it's a very basic thing. It's just that there are problems at work when you're looking at the house or finding your direction, when you're in a strange place. I don't think it's going to affect academic achievement very much [FT3]. 


\section{Situation that may Occur When You don't have Knowledge About the Concepts of "Location" and "Direction"}

A question -"What are your thoughts on the situations that an individual who does not have the knowledge of "location" and "direction" concepts might encounter?"- was asked to the participants in the study and the answers given by primary teachers were collected under the theme of "Difficulties". Under this theme, two sub-themes related to "in teaching-learning process" and "in real life" emerged. The results of the analysis of the data obtained from the opinions of the primary teachers are presented in Figure 5.

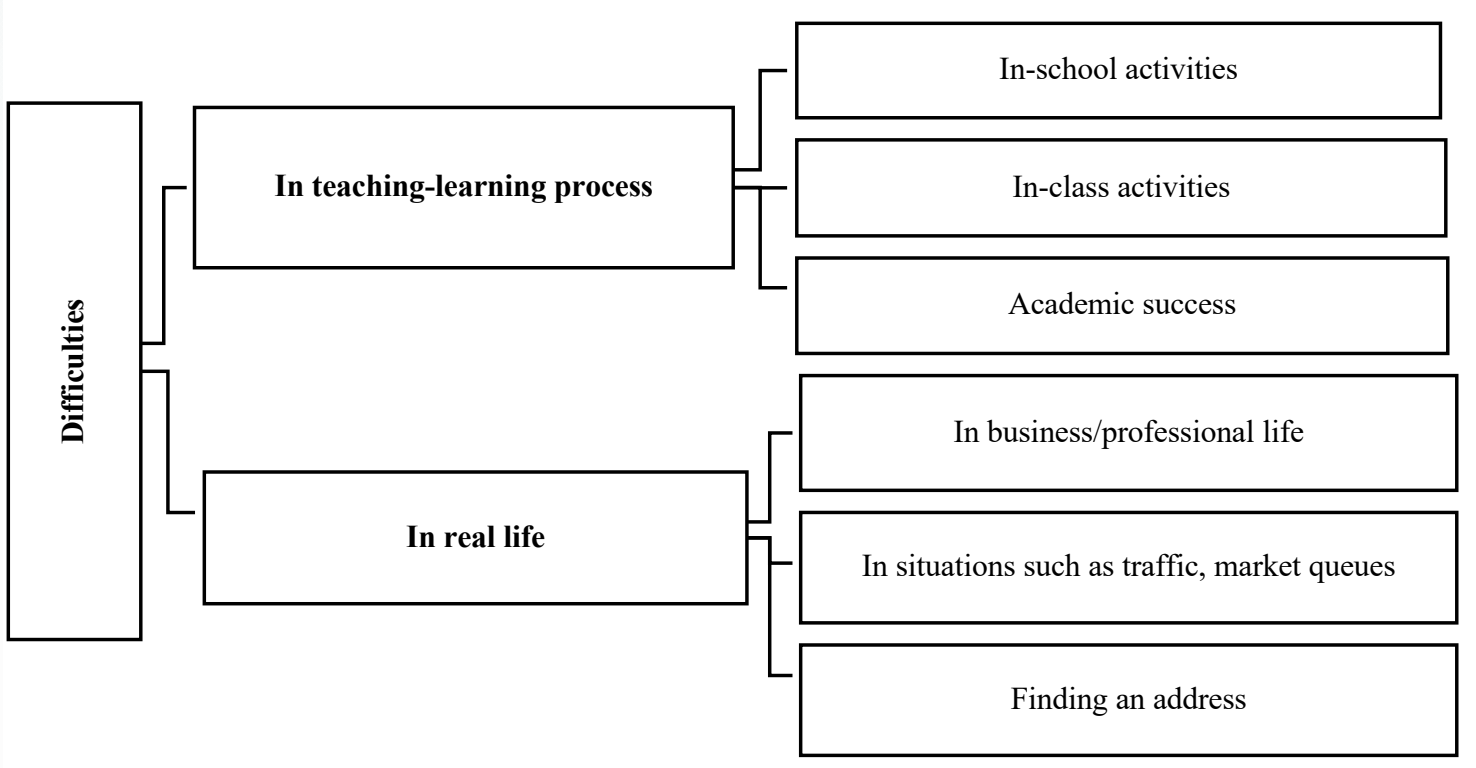

Figure 5. Possible difficulties that may occur when you do not have knowledge of the concepts of "location" and "direction"

Primary teachers' explanations are as follows:

First, he/she will most likely experience difficulties in daily life. For example, when he asks for address information, or sometimes when a relative comes to visit, he can probably be forced to give the address of his home [MT2].

Absolutely they will be in trouble. In everyday life, when driving, when trying to find a place, there will always be a problem that they will face [FT1].

Absolutely they will be in trouble. In everyday life, when driving, when trying to find a place, there will always be a problem that they will face. First, I think he will fail academically. And then I think that you will have difficulty perceiving certain things in society, in life. During a grocery store, someone behind you may have a moment's hesitation when they say, Ma'am, will you move to your right? It creates distressed situations, for example, in traffic. So this will be found in their lives as a big deficiency [FT2].

In business, many professions are now about finding directions. Navigation came out, but we still use the concepts of direction. Here, it prevents the loss of time. I think it makes a person 
happy that he is successful in his professional life and helps the person in his progress in his profession [MT3].

There's a lot of trouble with school activities. There can be problems with primary activities. Daily life can also be a problem at a later age. It's having parents with the child now, but he may have problems later in life [FT3].

In addition, a primary teacher expressed the possible difficulty a child can experience when they do not have knowledge of the concept of "location" and "direction" in the following words:

S/he may have a problem going forward. Or we use a lot of visuals when we follow the lesson in class. We'll get the kids on the board. Sometimes there are sections on the board. There are options. When I tell you to do the one on the left, son, if the boy doesn't know, s/he'll look at me. $\mathrm{S} /$ he can experience embarrassment, $\mathrm{s} /$ he can demoralize, that is, $\mathrm{s} / \mathrm{he}$ can feel an exclusion [MT1].

\section{Result and Discussion}

In this study, it was aimed to reveal the awareness of primary teachers about the teaching of the concepts of "location" and "direction". As a result of the analysis of the data obtained through the interview, the awareness of primary teachers about the teaching of these concepts was discussed within the scope of two themes: "Instructional necessity" and "academic and practical benefit". The study findings showed that participants were aware that the concepts of "location" and "direction" were a requirement in the curriculum, and that the teaching of these concepts provided benefits and convenience to students both in school life and in everyday life.

The study findings showed that all participants associated the concepts of "location" and "direction" with the Social Studies Lesson. They stated that they found that these concepts are related to this course because they are included in the curriculum as a subject of Life Science and Social Studies courses, and the opportunities to acquire knowledge and understanding about these concepts are collected under the roof of these two courses.

As a matter of fact, in the curriculum, expressions of acquisition related to the teaching of the concepts of "location" and "direction" in the Life Science and Social Science courses were included in the form of seven achievements in the course of Life Science, and two achievements in the course of Social Studies, making a total of nine achievements overall. In the Grade 1 primary course, the student learns about the basic concepts of finding the place and order of the class. In the Grade 2 primary course the students also draws a shape to understand the main directional aspects (East and West) and for being able to describe the location of their house.

In the Grade 3 primary course, students are to show the location of their school, class and house by drawing a sketch and to be able to describe all the main directions, to learn direction-finding methods, to have knowledge about the 
compass and to be able to distinguish land and sea on the sphere. In the Grade 4 primary course, it is aimed to acquisition map skills (Tuna, Demirci \& Gültekin, 2012).

The fact that the concepts of "location "and "direction" are also associated with the courses of Science, Mathematics and Turkish, it can be interpreted as showing the awareness of the primary teachers about the use of these concepts. As a matter of fact, in various studies on the subject (Aydınözü, Demirbaş \& Demir, 2020; Demirkaya, Çetin \& Tokcan, 2004), it has been found that the teaching of these concepts is taught in related subjects in Social Studies, Life Science, Science, Mathematics and Turkish courses.

Another important finding in the study relates to the fact that participants thought that primary school students had difficulty learning the concepts of "rightleft" regardless of class level. Participants stated that because aspects are an abstract subject, students have difficulty acquiring the right-left direction, and even if they embody it, they may be surprised whether children should understand the direction according to the corresponding shape or according to themselves, and they may mix the right-left direction.

In addition, participants expressed the need for many children of primary school age to practice understanding the right-left direction, and it was noted that because of the difficulty in understanding the right-left direction, they acquisition the rightleft direction with activity-based in-class and out-of-class practices. However, primary teachers also stated that it is difficult to teach right-left concepts using the speaking method. In the study conducted by Aydınözü, Demirbaş and Demir (2020), it was concluded that the concepts of direction were mixed.

Distinguishing right-left direction sounds more complicated to children than discriminating up-and-down. Because right and left can vary depending on the point of view. Distinguishing left - right is a complex neuro-psychological process that involves several high-level neurological functions (such as sensory and visual information, spatial function, language function, the ability to integrate memory). Compared to the concepts of up-down, near-far, the acquisition of right-left concepts develops relatively late in human development and is strengthened by experience. Girls are more confused with right-left concepts than boys (Jordan, Wüstenberg, Jaspers-Feyer, Fellbrich \& Peters, 2006).

Another important finding in the study relates to the use of location analysis activities. Participants stated that they used obvious reference points such as mosque, market, hospital, pharmacy around the relevant place to describe a place, address or location to the students. This indicates that primary teachers refer to the immediate environment in their location analysis; they prefer to use basic concepts 
such as "right-left, opposite, below-above" rather than the main and intermediate directions in their path and direction description.

In addition, this indicates that they prefer the environmentally oriented reference system from the reference systems that Golledge (2004) has stated regarding spatial memory and direction finding. As a matter of fact, Köşker (2012) also found in his research on spatial cognition competencies that class teacher candidates did not explain according to the distance unit (for example, 300 meters) when describing the directions; that is, they did not prefer to specify the distance; rather, they gave the directions by paying attention to the physical and architectural place elements around them.

As a result, it can be said that primary teachers are aware that the concepts of "location" and "direction" are among the important skills needed in the learningteaching process and in everyday life, and these concepts form the basis of a sense of movement. However, it is believed that the awareness of primary teachers should be increased in order to provide the basis for the ability to use maps and improve the ability to think spatially.

\section{References}

Aydınözü, D., Demirbaş, İ. \& Demir, B.D. (2020). Classroom teachers' opinions on gaining gains related to direction and direction finding in primary school students. International Journal of Geography and Geography Education (IGGE), 41, 59-72.

Bogdan, R.C., \& Biklen, S.K. (2003). Qualitative research for education: An introduction to theories and methods (4th ed.). New York, NY: Pearson Education Group.

Çepni, O. (2019). Location analysis. In Skills training in social studies (pp. 146-170), Eds.: B. Aksoy, B. Akbaba, B. Kilcan, Ankara: Pegem Academy.

Demirkaya, H., Çetin, T. \& Tokcan, H. (2004). The Methods That Can Be Used in Teaching the Concept of Direction in Primary Education. Gazi University Journal of Gazi Educational Faculty, 24(3), 39-70.

Dubois, P.J. \& Rousseau, E. (2020). A short philosophy of birds (Trans.: M. Erşen). İstanbul: Domingo Press.

Gagnier, K. \& Fisher, K. (2016). Spatial thinking: What it is, and why it matters for STEM education. available at: https://jscholarship.library.jhu.edu/bitstream/handle /1774.2/63010/spatialthinkingmastheadfinal.pdf?sequence=1\&isAllowed=y, 04.11 .2020

Glesne, C. (2013). Introduction to qualitative research (Trans. Eds.: P. Yalçınoğlu \& A. Ersoy). Ankara: Anı Press.

Golledge R.G. (2004). Spatial Cognition (pp. 443-452). In The Encyclopedia of Applied Psychology, Spielberger C. (Ed.), Amsterdam: Elsevier Ltd.

Jordan, K., Wüstenberg, T., Jaspers-Feyer, F., Fellbrich, A. \& Peters M. (2006). Sex differences in left/right confusion. Cortex, 42, 69-78. 
Dağ, N.; Aksoy, B.; Arslantaș, H. A. (2021). Awareness of primary teachers about teaching location...

Koç, H., Aksoy, B. \& Çiftçi, T. (2017). An examination of map literacy levels of students from various undergraduate programmes according to several variables: Cumhuriyet university sample. Erzincan University Journal of Education Faculty, 19(3), 301-321.

Köşker, N. (2012). Thoughts of prospective class teachers on their spatial cognitive adequacy. Zeitschrift für die Welt der Türken, 4(3), 161-172.

Leymun, S..O. (2017). The importance of case study research in educational settings. ENAD Online, 5(3), 369-385.

Miles, M.B. and Huberman, A.M. (1994). Qualitative data analysis. Thousand Oaks, CA: Sage.

National Research Council. (2006). Learning to think spatially. Washington, DC: The National Academies Press.

Patton, M. Q. (1990). Qualitative evaluation and research methods. USA: Sage.

Safi, H. (2010). Teachers' views on the development of the space perception skill in the social studies curriculum. Master's thesis, Marmara University Institute of Education Sciences, Istanbul.

Sönmez, Ö.F. \& Aksoy, B. (2012). Determination of primary education secondary stage students' map skill levels. Turkish Studies, 7(1), 1905-1924.

TDK (1998). Turkish dictionary-2 (K-Z). Ankara: Turkish Historical Society Printing House.

Tuna, F., Demirci, A. \& Gültekin, N. (2012). To what extent are basic geographic knowledge and skills used in society? Current situation analysis in direction, location and map skills. National Education, 195, 211-227.

Uttal, D.H., Meadow, N.G., Tipton, E., Hand, L.L., Alden, A.R., Warren, C., \& Newcombe, N.S. (2013). The malleability of spatial skills: a meta-analysis of training studies. Psychological Bulletin, 139(2), 352.

Yin, R.K. (1998). The abridged version of case study research. In L. Bickman, D.J. Rog (Eds), Handbook of applied social research methods, Sage, Thousand Oaks CA.

\section{Biographical Statements}

Nilgün DA ̌̆ works as an Assoc Prof. in Mersin University/Turkey, Department of Basic Education. Her research interests are Life Studies and Social Studies education.

Bülent AKSOY is a Professor at Gazi University/Turkey. His research interests are Geography Education, Social Studies Education and Political Geography studies.

Halis Adnan ARSLANTAŞ works at Eskişehir Osmangazi University, Faculty of Education, Department of Philosophical, Social and Historical Foundations of Education/Turkey. His research interests are educational philosophy, educational sociology and social studies. 